\title{
I'm not like everybody else: urbanization factors shaping spatial distribution of native and invasive ants are species-specific
}

\author{
Jérôme M. W. Gippet ${ }^{1} \cdot$ Nathalie Mondy $^{1} \cdot$ Julita Diallo-Dudek $^{2} \cdot$ Arnaud Bellec $^{1,2}$ • \\ Adeline Dumet $^{1}$ • Lubiana Mistler ${ }^{1}$ • Bernard Kaufmann ${ }^{1}$
}

(C) Springer Science+Business Media New York 2016

\begin{abstract}
Urbanization is a major global change inducing complex and multiple modifications of landscapes and ecosystems. The spatial distributions of organisms experiencing these modifications will likely shift specifically, depending on each species' response to each environmental modification induced by urbanization. We sampled two ant genera (Lasius and Tetramorium) at 1248 locations along an urbanization gradient in Lyon, France and used high resolution spatial layers for 18 spatial (e.g., open habitat fragmentation, bioclimatic data and surface temperatures) and temporal (e.g., comparison of Normalized Difference Vegetation Index between 1986 and 2015) environmental variables associated with urbanization. Coupling two different analytical methods (Outlying Mean Index and Boosted Regression Trees), we showed that each species' distribution was influenced by its own combination of environmental factors. Two morphologically cryptic Tetramorium species (T. sp.E and $T$. sp.U2) were both highly abundant but with opposite responses to urbanization: while $T$. sp.E was favored by urbanized habitat, T. sp.U2 avoided urbanized areas. Among Lasius species, we detected 63 occurrences of the invasive ant Lasius neglectus, the distribution of which was favored only by
\end{abstract}

Electronic supplementary material The online version of this article (doi:10.1007/s11252-016-0576-7) contains supplementary material, which is available to authorized users.

Jérôme M. W. Gippet

jgippet@gmail.com

1 Université de Lyon, UMR5023 Ecologie des Hydrosystèmes Naturels et Anthropisés, ENTPE, CNRS, Université Lyon 1, Villeurbanne, F-69622 Lyon, France

2 UMR5600 Environnement Ville Société, Université Lyon 3, CNRS, Université de Lyon, 86 rue Pasteur, 69365, Cedex 07 Lyon, France embankments along roads. We found that, even at this reduced spatial scale, climatic effects influenced most species and interacted with urbanization factors.

Keywords Urbanization · Global change $\cdot$ Species distribution $\cdot$ Biological invasions $\cdot$ Formicidae $\cdot$ Lasius neglectus

\section{Introduction}

The pace of urbanization has dramatically accelerated over the past decades to become a major concern, severely impacting biodiversity dynamics, ecosystems functioning, as well as human well-being (Grimm et al. 2008a). Urbanization can be defined as the modification of an ecosystem to support dense human populations and their activities (Gaston 2010). In urban areas, original plant communities are partially or totally replaced by impervious surfaces (e.g., roads, concrete and building), exotic plant species and bare ground (Heterick et al. 2013). Outside of cities, the agricultural area necessary to feed urban populations is growing with the pace of urbanization, replacing diverse native plant communities by cultivated monospecific patches (Flinn and Vellend 2005). These land cover changes are responsible for habitat fragmentation (Jenerette and Potere 2010) and for an increase in openvegetation patches (typically lawns) to the detriment of forests (James and Bound 2009, Smith et al. 2015). Land cover changes are also characterized by spatial and temporal dynamics as they follow the development of cities. Among the direct consequences of land use changes are the alteration of physical characteristics of surfaces, i.e. emissivity, albedo, and thermal conductivity. Furthermore, removing plant cover reduces evaporative cooling and modifies radiative fluxes in urban areas. These changes induce warmer surface and air 
temperature in urban areas, particularly at night-time, a phenomenon termed Urban Heat Island (UHI) effect (Dousset et al. 2011). Urban areas are also subjected to heavier air, soil and water pollution than surrounding rural areas (Grimm et al. 2008a).

In addition, urban areas are exposed to frequent introductions of exotic species through national and international commercial exchanges, as well as to the secondary spread of invasive species. Secondary spread is exacerbated by recurrent human-mediated transport facilitating dispersal (Hodkinson and Thompson 1997, King et al. 2009) and by increased habitat invasibility associated with disturbed landscapes, which facilitate establishment (Alpert et al. 2000; With 2002; Vonshak and Gordon 2015).

Changes associated with urbanization therefore constitute new environmental filters for biodiversity, modifying species' distribution patterns and affecting community composition along the urbanization gradient (Van Nuland and Whitlow 2014). Several studies have already shown that assemblage parameters such as native and invasive species richness and abundance are affected by urbanization for a wide range of taxa (Hansen et al. 2005). While urban environments are often described as species-poor ecosystems (Niemelä and Kotze 2009, but see Pećarević et al. 2010), several studies have shown that suburban areas can display high species richness and diversity because of greater habitat heterogeneity, intermediate disturbance regime and invasive species enrichment (Angold et al. 2006; Vonshak and Gordon 2015, Menke et al. 2011). Further studies have shown that community responses vary depending on the taxonomic group considered (Croci et al. 2008; McKinney 2008; Vergnes et al. 2012). Since Blair's classification of species responses to urbanization (Blair 1996), several authors categorized species into urban exploiters, urban tolerant and urban avoiders (McIntyre 2000; Kark et al. 2007). However, this characterization has been criticized as over-simplistic and prone to masking nuanced or complex species responses to urbanized landscapes (Conole 2014). While urban-rural gradient approaches have been widely used to describe species and community responses to urbanization (McDonnell and Hahs 2008), precisely identifying which environmental factors are implicated has become a major issue of urban biodiversity studies (Philpott et al. 2014, Turrini and Knop 2015). As the environmental changes induced by urbanization depend on the interactions between multiple environmental factors and species biological traits (Poff 1997; Brown et al. 2009; Verberk et al. 2013), species responses to urbanization are likely to be specific and to depend on the local environmental background, which includes climate or social and economic activities (Grimm et al. 2008b; Oleson et al. 2015). Consequently, clearly identifying environmental factors associated with urbanization and understanding their impacts on ecological dynamics should constitute a first step towards evaluating and predicting the consequences of urbanization on biodiversity. To this end, Arthropods have recently been pointed out as highly relevant organisms, and among them, ants (Stringer et al. 2009; Menke et al. 2011; Bang and Faeth 2011, Ślipiński et al. 2012; Heterick et al. 2013), because they are among the few taxa able to establish stable populations in densely urbanized habitat such as big city cores (Pećarević et al. 2010; Guénard et al. 2015; Savage et al. 2015). Ants have also been identified as effective city scavengers (Youngsteadt et al. 2014) and several invasive ant species are known to be dominant in urban habitats (Ward 1987; Suarez et al. 1998; Buczkowski and Bennett 2008). Community ecology studies have shown that ant species richness and community composition differ along urban to rural gradients (Ślipiński et al. 2012; Heterick et al. 2013) but most of them focused on forested habitat and urban parks (e.g., Yamaguchi 2005; Clarke et al. 2008; Carpintero and Reyes-López 2014) while lawns and open-vegetation green spaces, the most common habitat type in urbanized landscapes, have been neglected (but see Uno et al. 2010). These habitats are, however, likely to host rich ant communities as many ant species are open and edge habitat specialists. Among these, the genera Lasius and Tetramorium are particularly well represented: they are known to be both highly species diverse and exhibit broad spatial distributions ranging over most of continental Europe. Both contain species that invasive in Europe, such as Lasius neglectus (Ugelvig et al. 2008), or in North America, such as Lasius alienus, Tetramorium sp.E and Tetramorium tsushimae (Steiner et al. 2008), as well as species highly tolerant to urban conditions such as Lasius niger (Vepsäläinen et al. 2008).

We conducted surveys of Lasius and Tetramorium ants in the landscape of the urban area of Lyon, which is the second largest in France. The aims of our study were (i) to describe Lasius and Tetramorium responses to environmental changes associated with urbanization and (ii) to identify landscapescale factors shaping the spatial distributions of species. Our main hypothesis was to find species-specific response patterns to urbanization: as species' ecological niches are characterized by unique combinations of environmental optima, therefore each species should be affected by a particular set of environmental features and have its own response pattern along the urbanization gradient. Additionally, we predicted that the occurrence of invasive species should be associated with factors related to the intensity of human activities.

\section{Methods}

\section{Study area and sampling}

The study was conducted in the urban area of Lyon, France (Fig. 1), and along the two major sets of transportation infrastructures serving the city (A7 motorway, train and Rhône 
Fig. 1 Sampling locations in the urban area of Lyon, France. Black dots indicate sampling locations, altitudes are represented by shades of green, with darker shades showing higher altitudes

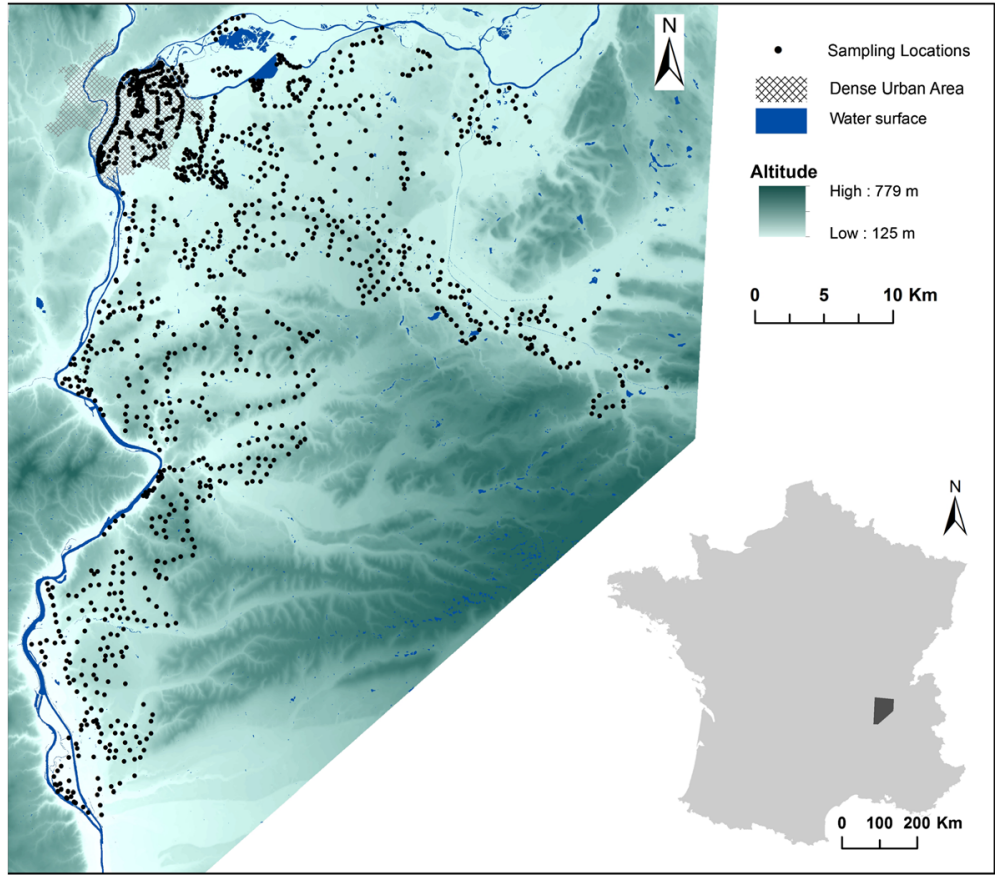

River to the South and West, A43 motorway to the East) which concentrate industrial and commercial activities and are consequently important features of urban gradients. In 2012, the Lyon urban area hosted 2,214,000 people and covered $6017 \mathrm{~km}^{2}$. Lyon is located at the confluence of the Rhône and Saône rivers and has a continental climate with Mediterranean influences. Mean temperatures are $3.2{ }^{\circ} \mathrm{C}$ in the coldest month (January) and $21.9{ }^{\circ} \mathrm{C}$ in the warmest month (July), with an annual mean temperature of $12.3{ }^{\circ} \mathrm{C}$. The annual average rainfall is $820 \mathrm{~mm}$ (Infoclimat.fr 2011).

1248 locations (Fig. 1) were sampled within this area, during spring and summer 2011, 2012 and 2013, following the method of Roura-Pascual et al. (2009). Sampling locations were herbaceous patches, with or without trees and shrubs, and generally close to or along roadsides. They were randomly selected along road transects and were located at least $500 \mathrm{~m}$ apart when outside the city center and $200 \mathrm{~m}$ apart when inside the city center. Sampling was performed by teams of two to five persons for an added search time of $40 \mathrm{~min}$ (the actual sampling time depended on the number of samplers, e.g., four samplers took $10 \mathrm{~min}$ per site; two samplers, $20 \mathrm{~min}$ per site) within a radius of $15 \mathrm{~m}$, and only when air temperatures were comprised between $16^{\circ} \mathrm{C}$ and $28^{\circ} \mathrm{C}$ (Seifert 2007). Sampling was a direct search of ants nest and trails on the ground, trees and shrubs, followed by hand collecting using an entomological aspirator. Ants from the genera Lasius and Tetramorium were collected (except for hypogeic Lasius species). Spatial coordinates of sampling locations were recorded and imported into ArcGIS v.10.1 (http://www.esri. com/software/arcgis).

\section{Morphological and molecular identification}

All collected ants were preserved in $96^{\circ}$ alcohol at $-20^{\circ} \mathrm{C}$ and morphologically identified to genus or species whenever possible, following Seifert (2007). One individual per colony of Tetramorium and taxonomically ambiguous Lasius species (i.e. with short or appressed scape setae) were systematically identified using Cytochrome Oxydase I (COI).

DNA was extracted from whole individuals for Tetramorium, from head and thorax only for Lasius to remove formic acid. Lasius ants were crushed and then mixed with $150 \mu$ l of hot $\left(90^{\circ} \mathrm{C}\right)$ Chelex ${ }^{\circledR} 100$ then cooled; Tetramorium ants were crushed and then mixed with $150 \mu \mathrm{l}$ of roomtemperature Chelex ${ }^{\circledR} 100$. In both cases, $10 \mu \mathrm{L}$ of proteinase $\mathrm{K}(15 \mathrm{mg} / \mathrm{mL})$ were added after crushing and cooling, and the solution was incubated at $55{ }^{\circ} \mathrm{C}$ overnight (Casquet et al. 2012).

DNA was amplified by PCR using specific primers developed from complete COI sequences found in Genbank (COI_neg_F1, TTATTAATGAYGGAGTYGGAACAG GATG; COI_neg_R1, CTCGTCGTTATTCAGATT AYCCAGATA, derived from PAT L2-N-3014r (Simon et al. 1994). PCR Reactions were carried out in $35 \mu \mathrm{L}$ solutions with $0.17 \mu \mathrm{M} / \mu \mathrm{l} \mathrm{dNTPs}, 0.1 \mu \mathrm{g} / \mu \mathrm{l}$ BSA (New England Biolabs, Ipswich, USA), $0.16 \mu \mathrm{M} / \mu$ l of each primer, $0,04 \mathrm{U} /$ $\mu \mathrm{l}$ Taq Polymerase (Biolabs), 1X PCR Buffer (Biolabs), and $4 \mu \mathrm{l}$ of DNA. Cycling was conducted on a PTC-200 (MJ Research) thermal cycler with following parameters: (i) initial denaturation for 2 min at $94{ }^{\circ} \mathrm{C}$, (ii) 40 cycles with denaturation for $30 \mathrm{~s}$ at $94{ }^{\circ} \mathrm{C}$, annealing for $30 \mathrm{~s}$ at $48{ }^{\circ} \mathrm{C}$ and extension for $30 \mathrm{~s}$ at $72{ }^{\circ} \mathrm{C}$; (iii) final extension for $1 \mathrm{~min}$ at $72^{\circ} \mathrm{C}$. In 
Europe, the genus Tetramorium has numerous cryptic taxa (Schlick-Steiner et al. 2006), and COI sequencing is the only reliable means to identify them. DNA was amplified by PCR using specific primers developed from longer stretches of COI from the literature (Schlick-Steiner et al. 2006), with the following sequences (Tetra_F: TAGCATCTAATR TCTTTCAYAGAGG; Tetra_R: AGTATCAGGATA ATCTGAGTAYCGAC); PCR reagents and conditions were identical to Lasius PCRs. All PCR products were purified sequenced and ran on a 3730xl DNA Analyzer (Applied Biosystems) by a service provider (BIOFIDAL, Vaulx-enVelin). All obtained sequences were compared to existing sequences present in Genbank using Blast-n.

\section{Environmental factors associated with urbanization}

18 environmental factors associated with urbanization and climate were extracted from various sources (see Table S1). Variables extraction was conducted using ArcGIS 10.1.

Land cover variables were extracted from an initial raster layer (1.5 m spatial resolution) obtained from a three-step process. First, we extracted topographical vectorial data from national maps (BD TOPO ${ }^{\circledR}$ (2013) IGN) and Graphical Parcel Register (RPG 2012, www.data.gouv.fr). Second, unassigned surfaces (essentially impervious surfaces and open-vegetation surfaces) were processed with an image processing method using SPOT 6 imagery obtained by GEOSUD (http://geosud. teledetection.fr/) (1.5 m spatial resolution) to assign each pixel to a "green" or a "grey" surface. Third, all layers were merged to produce a land cover map (1.5 m resolution) with five different classes: water, forest, open-vegetation (i.e. open spaces with permanent grass cover such as lawns, meadows and pastures), agricultural and impervious. For each sampling location, areas of each land cover class (except water) were calculated within both a 50 and a $500 \mathrm{~m}$ radius buffer.

Surface temperatures (ST) were calculated from remote sensing data (Diallo-Dudek et al. 2015) based on Landsat 8 imagery from the 21 st of July, 2013. For each sampling location, mean surface temperatures were calculated within a $50 \mathrm{~m}$ radius buffer.

A land cover change index (deltaLC), representing land cover changes over the last 31 years, was produced following a three-step process. First, we produced NDVI (Normalized Difference Vegetation Index) from Landsat images (30 m resolution, using Red and Near-Infrared) from two dates: 25th of June, 1986, and 11th of July, 2015. Second, for each NDVI, we determined a threshold value that best discriminated urbanized from non-urbanized pixels. To choose the best threshold at each date, we produced binary urbanized versus nonurbanized raster layers for eleven different thresholds (from 0.15 to 0.25 , incremented by 0.01 ; with 0 : non-urbanized, 1 : urbanized), and randomly selected 1000 pixels in each Landsat images (1986 and 2015). We then visually assigned each pixel to "urban" or "non-urban", ambiguous pixels being removed, for a final total of 354 and 400 correctly assigned pixels for 1986 and 2015 respectively. We finally used the Kappa-Cohen's coefficient (Cohen 1960) to select the best NDVI threshold for each date, which is the threshold for which the best agreement score between our visually discriminated pixels and the threshold-induced classification was obtained. For the two dates, the best agreement score was 0.71 , indicating that our classification was moderately accurate because of initial data quality and methodological limitations, which were likely to add stochastic variability to the final variable (i.e. deltaLC). Third, using the best thresholds (i.e. 0.22 and 0.21 for 1986 and 2015 respectively), we obtained a binary raster layer for each date and, by subtraction, a final third raster map containing three different values: -1 (changes from vegetated to urbanized between 1986 and 2015), 0 (no changes between 1986 and 2015) and 1 (changes from urbanized to vegetated between 1986 and 2015). We finally calculated the mean change index within a $100 \mathrm{~m}$ radius buffer around each sampling location.

As a measure of open habitat fragmentation (OHFrag), we used the mean area of open-vegetation patches (e.g. lawns, meadows, semi-natural grasslands), calculated within a $500 \mathrm{~m}$ radius buffer around each sampling location.

The intensity of human activities was assessed using three variables: distance from sampling locations to the closest main road (DMainRoad), distance from sampling locations to the closest embankment (Dbanks), and secondary road network density within a $100 \mathrm{~m}$ radius (RoadsDensity). Main and secondary roads networks as well as embankments were extracted from BD TOPO ${ }^{\circledR}$ (2013) IGN. Roads and embankments were considered because the former are often related to invasive species occurrences (Prasad et al. 2010; Rouifed et al. 2014) while the latter are intrinsically associated with soil transportation at short to medium distances and are therefore likely to be implicated in the spatial spread of invasive species, especially ants.

Altitudinal and climatic variables were considered because our most southern sampling locations showed stronger Mediterranean climatic influences and because, even if sampling was designed to minimize altitudinal variation, sampling locations ranged from 132 to $405 \mathrm{~m}$ above sea level. Altitudinal data were obtained from BD Alti ${ }^{\circledR}(2013,25 \mathrm{~m}$ spatial resolution) IGN and we used two Bioclim variables (Hijmans et al. 2005): mean annual temperature and mean annual precipitation (Table S1).

All 18 variables (Table S1) were classified as follows: land cover (LC, containing 8 variables), surface temperature (ST, 1 variable), temporal land cover change (deltaLC, 1 variable), open habitat fragmentation (OHFrag, 1 variable), human activities (HA, 3 variables) and altitudinal/ climatic effects (CE, 3 variables). 
In order to avoid variables redundancy and to facilitate interpretation, we reduced the number of variables using principal component analyses (PCA), performed in classes LC and $\mathrm{CE}$ as they contained highly collinear variables (Fig. S1). This operation enabled us to reduce the initial number of variables from 18 to 10 by extracting a set of synthetic orthogonal (uncorrelated) variables (Table 1).

\section{Data analysis}

All statistical analyses were performed in R ( $\mathrm{R}$ Development Core Team 2014).

Data were analyzed using a multivariate ecological niche analysis (Outlying Mean Index, OMI; Doledec et al. 2000; R package ade4, Dray and Dufour 2007) and machine learning method (Boosted Regression Trees, BRTs; Elith et al. 2008; R package dismo, Hijmans et al. 2011). These two methods investigate species-environment relationships in different ways. While OMI allows a simultaneous comparison of the response of all species to environmental factors, BRT investigate each species individually and allows a more specific assessment of species-environment relationship (as described below).

The Outlying Mean Index analysis maximizes the variance in species occurrences along ordination axes obtained from the input of environmental factors. This method assesses for each species the marginality or OMI (i.e. the difference between the average environmental conditions found for a species and the average environmental conditions for all locations), the tolerance (i.e. the breadth of the species' niche) and the residual tolerance (i.e. the variation in species occurrence not accounted for by the main gradient). To identify the main factors affecting species marginality, for each species and for each environmental factor, we measured the significance of the deviation of average factor values in the locations used by the species and the average factor values in all locations by running permutations tests (9999 permutations and using Bonferroni correction).
Boosted Regression Trees is a machine learning algorithm that uses a combination of decision trees and boosting methods to fit models. BRT has strong predictive performance, allows nonlinearities of predictor variables and detects interactions between them. It also enables predictor variables to be classified by their relative contributions (Elith et al. 2008). This method is relatively new in ecological studies and globally outperforms other more traditional methods (Elith et al. 2006). BRT models were fitted using a tree complexity of 5 and a learning rate of 0.001 . Ten-fold cross validation was used by randomly selecting $50 \%$ of the sampling locations for model fitting and the remaining $50 \%$ for model validation. This enabled the calculation of two values for each model: the explained deviance and the discrimination as measured by the area under the receiver operator characteristic curve (AUC). Explained deviance indicates the goodness-offit between predicted and raw values, it was expressed as a percentage of the null deviance. AUC indicates the degree to which fitted values discriminate between observed presences and absences. AUC values range from 0.5 (discrimination no better than random) to 1 (perfect discrimination) (Leathwick et al. 2008; Radinger et al. 2015).

We identified the main factors affecting species distribution by coupling permutation tests and BRT relative contribution outputs. We only retained variables that showed significant effects according to permutation tests and that contributed to more than $10 \%$ of total variance according to BRT models.

\section{Results}

From the 1248 sampled locations, we obtained a total of 2503 Lasius and Tetramorium occurrences with 7 and 4 species for each genus respectively. Lasius niger and Tetramorium sp.E were the most frequent species, respectively found in 74.9 and $49.1 \%$ of locations.

Lasius neglectus, known to be invasive in Europe, was found in 69 sites $(5.5 \%$ of the sampling locations), a large

Table 1 Environmental factors used for Outlying Mean Index and Boosted Regression Trees analyses

\begin{tabular}{|c|c|c|c|c|c|}
\hline Factor & Category & Description & Mean & Min & $\operatorname{Max}$ \\
\hline $\mathrm{LC} 1$ & Land Cover & from low to high impervious cover & 0.00 & -1.89 & 1.93 \\
\hline $\mathrm{LC} 2$ & & from low to high agricultural cover & 0.00 & -2.56 & 3.65 \\
\hline $\mathrm{LC} 3$ & & From mostly forest to mostly open vegetation & 0.00 & -5.04 & 1.88 \\
\hline ST & Urban heat island effect & Surface temperature $\left({ }^{\circ} \mathrm{C}\right)$ & 32.82 & 25.77 & 40.78 \\
\hline deltaLC & Land cover change & urbanized vs vegetated, between 1986 and 2015 & -0.02 & -1.00 & 1.00 \\
\hline OHFrag & Open Habitat Fragmentation & Mean patch area $\left(-\log \left(\mathrm{m}^{2}\right)\right)$ & -6.79 & -10.63 & -4.32 \\
\hline DMainRoad & Human Activities & Distance to primary road network $(\log (m))$ & 6.15 & -0.92 & 8.59 \\
\hline DEmbankments & & Distance to embankments $(\log (\mathrm{m}))$ & 4.97 & -1.28 & 7.31 \\
\hline RoadsDensity & & Secondary road network density $\left(\mathrm{m} / \mathrm{km}^{2}\right)$ & 13,719 & 0.00 & 38,923 \\
\hline CE1 & Climatic Effects & Hot, dry and low altitude vs cold, wet and high altitude & 0.00 & -1.73 & 3.35 \\
\hline
\end{tabular}


number of occurrences for this species considering our reduced spatial scale. For comparison, to date, 174 occurrences of $L$. neglectus were known for all Europe, of which 47 in France (Espadaler and Bernal 2015). The other common species were $T$. sp.U2 (24.7\%), L. alienus (21.1\%), L. emarginatus (16.3\%), and L. paralienus (4.3\%) (Table 2).

The first two axes of the OMI explained $88.9 \%$ of total inertia (axis 1: $79.16 \%$ and axis 2: $9.76 \%$ ) (Fig. 2). The first axis was a mix of climatic and urbanization effects, opposing fragmented, impervious, hot and dry locations to nonfragmented, non-impervious, cold and wet locations. The second axis was mainly negatively correlated to two factors: ST (surface temperature) and LC3 (amount of forest versus openvegetation). Because forests induce evaporative cooling, they are likely to be associated with low surface temperatures (Fig. 2, Table 3).

The investigation of ecological niche parameters indicated that a large part of the total variance in species occurrences remained unexplained, with residual tolerance ranging from $63.1 \%$ to $89.4 \%$ (Table 4 ). However, species exhibited marginality scores ranging from $0.2 \%$ (L. niger), indicating a very weak (although significant) difference from the environmental average conditions, to $13.3 \%$ (T. sp.U2). Tolerance ranged from $9.9 \%$ (L. paralienus) to $30.1 \%$ (L. emarginatus) (Table 4).

Tetramorium species were mainly spread along the first axis and showed opposite positions (Fig. 2). T. sp.E and T. sp.U2 respectively showed positive and negative associations with fragmented open-vegetation patches, impervious areas and hot/dry climate (Fig. 2).

Lasius species were spread along the two axes. Lasius niger was the most central species, as indicated by its OMI score. L. alienus, L. emarginatus and L. paralienus occurrences were associated with the less impervious, less fragmented and cold/wet part of the environmental gradient. Finally, L. emarginatus and L. neglectus occurrences showed positive scores along the second axis, indicating that they were likely to be associated with low surface temperature or forested areas.
BRT provided 'acceptable' (AUC $=0.7-0.8)$ to 'excellent' $(\mathrm{AUC}=0.8-0.9)$ model performance for 4 out of 7 species, but weak model performance for $L$. alienus, $L$. emarginatus and L. niger ( $\mathrm{AUC}=0.6-0.7$ ) (Leathwick et al. 2008). Levels of explained deviance were relatively low (ranging from $3.32 \%$ (for L. niger) to $24.13 \%$ (for T. sp.U2) but in accordance with OMI results (Fig. 3, Table 4, Table 5).

Species distributions were affected by at least 2 environmental factors (except L. emarginatus with 3 factors). Climatic effects were detected for 5 species out of 7, which confirmed field observations attesting to stronger Mediterranean climatic influences in the South of the study area. $L$. neglectus and $T$. sp.E distributions were negatively correlated with CE1, i.e. favored by hot/dry climatic conditions, whereas L. emarginatus, L. paralienus and T. sp.U2 showed the opposite pattern (Fig. 2, Table 6). Land cover factors affected $L$. alienus (LC1: negatively correlated with impervious surfaces), L. emarginatus (LC3: negatively correlated with open vegetation and positively with forested areas), L. paralienus (LC2: negatively correlated with agricultural areas) (Table 6). L. emarginatus occurrence was negatively correlated with surface temperatures. Land cover change was negatively correlated with $L$. alienus, i.e. it is favored by newly urbanized areas, and positively correlated with L. niger occurrences, which is favored by newly vegetated areas (Table 6). Land cover change was not correlated to any other species occurrences, however, despite acceptable overall kappa scores, some agricultural areas were misclassified as urban, due to absence of plant cover at the date of the imagery, thereby decreasing the accuracy of the measure in parts of the landscape. Only occurrences of Tetramorium species were directly correlated to fragmentation: while $T$. sp.U2 was negatively affected by open habitat fragmentation, $T$. sp.E showed the opposite pattern (Table 6). Among factors related to human activities, only distance to embankments influenced ant distributions: the invasive ant $L$. neglectus occurred more often in locations close to embankments whereas L. niger
Table 2 List of sampled Lasius and Tetramorium ant species. Only bold-typed species were used in further analyses, the others being rare

\begin{tabular}{llll}
\hline Species & Code & Number of occurrences & Prevalence (\%) \\
\hline Lasius alienus & las_ali & 263 & 21.06 \\
Lasius brunneus & las_bru & 36 & 2.88 \\
Lasius emarginatus & las_ema & 203 & 16.25 \\
Lasius neglectus & las_neg & 69 & 5.52 \\
Lasius niger & las_nig & 935 & 74.86 \\
Lasius paralienus & las_par & 54 & 4.32 \\
Lasius platythorax & las_pla & 12 & 0.96 \\
Tetramorium caespitum & tet_cae & 2 & 0.16 \\
Tetramorium moravicum & tet_mor & 8 & 0.64 \\
Tetramorium sp.E & tet_spe & 613 & 49.08 \\
Tetramorium sp.U2 & tet_spu & 308 & 24.66 \\
\hline
\end{tabular}


Fig. 2 OMI analysis plot. The first axis is horizontal; the second axis is vertical. The origin of the plot represents the mean environmental conditions. Environmental factors (boxed) are represented as vectors; their relative size reflecting their influence (longer lines indicate greater influence) and their direction indicating their correlation to each axis. Species are indicated by their abbreviation code, their position on the factorial plane reveals the degree of difference of their ecological niche to the mean environmental conditions and their correlation to each axis

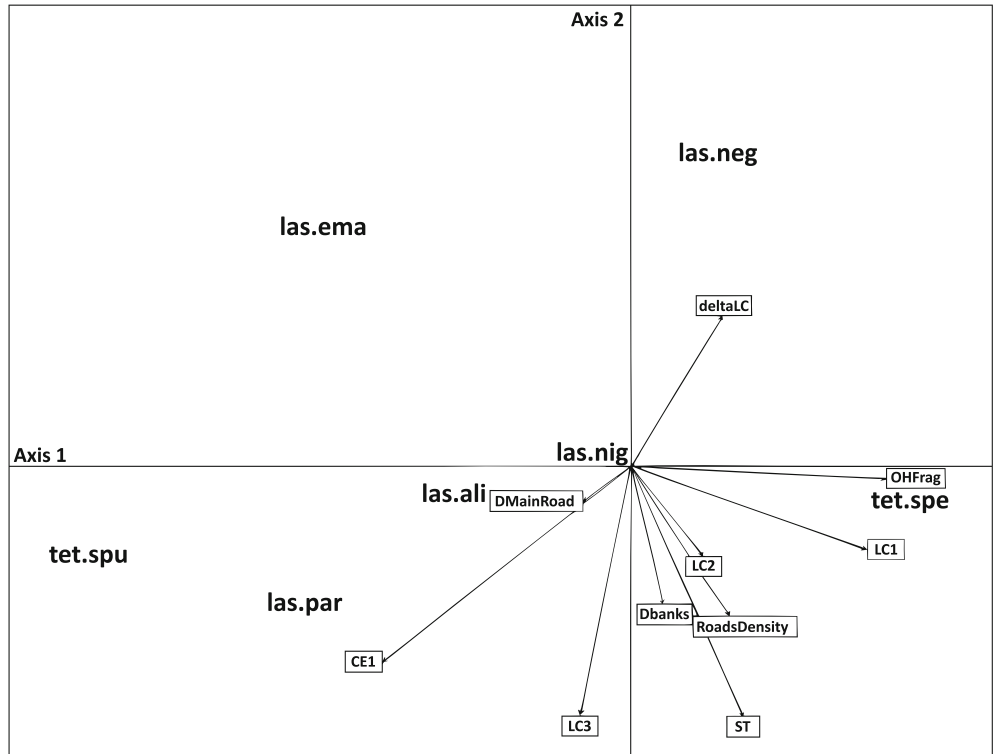

showed the opposite pattern (Table 6) (See Table S2 for details). The interpretation of functions fitted by BRT models were made complicated by interaction effects, even for factors that were not previously found significant: BRT models detected 3 species for which there were strong interaction effects (i.e. interactions with the highest interaction scores): L. neglectus, $L$. paralienus and T. sp.U2. Among these interactions, the strongest implicated climatic factors (i.e. CE1), as well as distance to embankments (DBanks) for L. neglectus (Fig. 3a), the agriculture related land cover factor (LC2) for L. paralienus (Fig. 3b) and surface temperatures for T. sp.U2 (Fig. 3c).

\section{Discussion}

In the present study, ant species exhibited specific responses to environmental changes induced by urbanization. As

Table 3 Correlation between each environmental factor and the first two axes of the OMI. The first axis explained $79.16 \%$ and the second axis $9.76 \%$ of variation

\begin{tabular}{lll}
\hline Variables & Axis 1 scores & Axis 2 scores \\
\hline LC1 & 0.2789 & -0.0330 \\
LC2 & 0.0855 & -0.0357 \\
LC3 & -0.0603 & -0.0989 \\
ST & 0.1324 & -0.0993 \\
deltaLC & 0.1078 & 0.0599 \\
OHFrag & 0.3003 & -0.0049 \\
DMainRoad & -0.0566 & -0.0137 \\
DBanks & 0.0395 & -0.0547 \\
RoadsDensity & 0.1150 & -0.0596 \\
CE1 & -0.2921 & -0.0777 \\
\hline
\end{tabular}

urbanization generates a mixture of several environmental changes, the distribution of each species was affected by a subset of these changes and the factors composing these subsets varied greatly depending on the species considered. Rather unexpectedly, we showed that, even at a reduced spatial scale, climate had as strong explanatory contribution for species distribution, and that it often had interactive effects with urbanization factors. Furthermore, as expected, invasive species distributions (i.e. L. neglectus) were related to human activities, here the distance to road embankments; L. neglectus was also surprisingly prevalent in the landscape as our study did more than double the number of known occurrences (Fig. 4b) for this species in France, which is likely to be of concern as this kind of landscape invasional pattern is probably a widespread situation both in France and in the rest of Europe.

We found that ecological niche marginality and ecological niche breadth varied across ant species (OMI range from 0.2

Table 4 Niche parameters of the seven species (in percentages of total variability). OMI represents the distance of the mean conditions of locations occupied by the species to the mean environmental conditions; Tolerance indicates niche breadth; rTol is the residual tolerance, i.e. the percentage of unexplained variability

\begin{tabular}{llll}
\hline Species & Marginality (\%) & Tolerance (\%) & rTol (\%) \\
\hline L. niger & 0.2 & 10.5 & 89.4 \\
L. alienus & 2.2 & 16.00 & 81.7 \\
T. sp.E & 3.7 & 28.50 & 67.9 \\
L. emarginatus & 6.8 & 30.10 & 63.1 \\
L. paralienus & 8.9 & 9.90 & 81.2 \\
L. neglectus & 10.3 & 11.80 & 77.9 \\
T. sp.U2 & 13.3 & 12.70 & 74.00 \\
\hline
\end{tabular}


Fig. 3 Plot of the most important pair-wise interactions detected by BRTs. a Interaction between CE1 (Climatic Effects) and Dbanks (Distance to Embankments) for L. neglectus; $\mathbf{b}$ Interaction between CE1 and LC2 (Land Cover factor associated with agricultural surfaces amount) for L. paralienus; $\mathbf{c}$ Interaction between CE1 and ST (Surface Temperature) for $T$. sp.U2
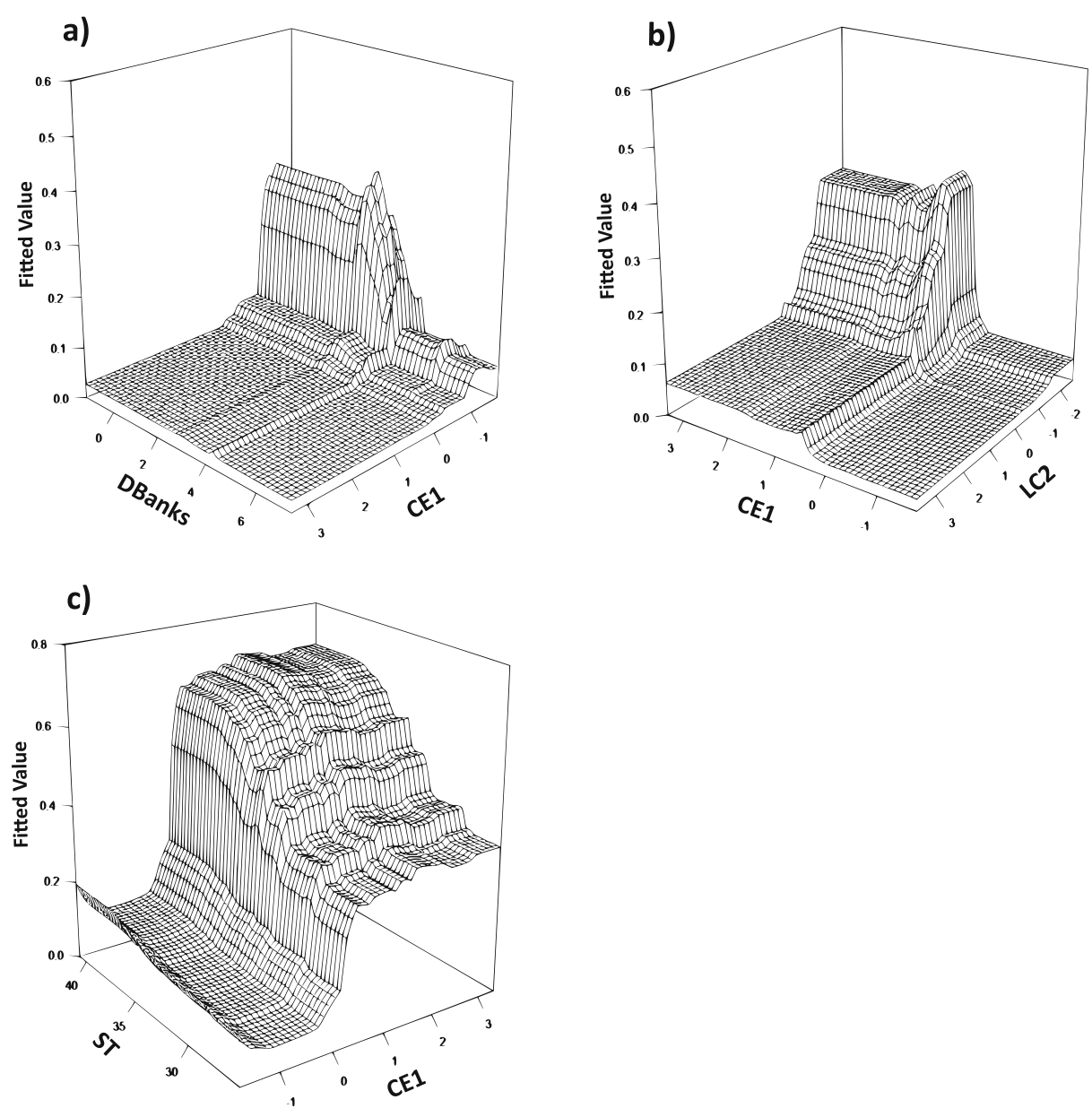

to $13.3 \%$ and Tolerance from 9.9 to $30.1 \%$ ). These results indicated that most ant species responded to changes induced by urbanization. Nevertheless, a large part of the variability in species-environment relationships remained unexplained (Fig. 2, Table 4), highlighting the need to take into account other habitat and microhabitat factors directly or indirectly associated with urbanization such as soil pollution (Eeva et al. 2004) or structural properties of soils (Boulton et al. 2005). This limit in explanative power could also be explained by the presence/absence nature of the dataset. Abundance data would improve the description of species-environment relationship, but such data require far more intensive sampling, which would limit the number of sampling locations and consequently hamper the ability to detect low-density species, such as L. neglectus in our landscape (Joseph et al. 2006).

Our study clearly showed a species-specific response to urbanization as each ant species was affected by a specific combination of factors (Table 6) and as only Tetramorium species were impacted, although in opposite directions, by the same factors (open habitat fragmentation and climate).

Among Tetramorium species detected in the sampling area, only two were common: $T$. sp.E and $T$. sp.U2. These species have not been formally described yet as they belong to a

Table 5 Predictive performance of BRT models for each species

\begin{tabular}{llll}
\hline Species & \% Explained Deviance & AUC mean & AUC standard errors \\
\hline L. alienus & 5.649861 & 0.67081 & 0.02507422 \\
L. emarginatus & 6.385291 & 0.69566 & 0.01883043 \\
L. neglectus & 7.050766 & 0.70128 & 0.03554388 \\
L. niger & 3.320513 & 0.63409 & 0.01752321 \\
L. paralienus & 10.310401 & 0.74345 & 0.0366056 \\
T. sp.E & 10.529285 & 0.71924 & 0.01750342 \\
T. sp.U2 & 24.129223 & 0.83013 & 0.01207758 \\
\hline
\end{tabular}


Table 6 Factors influencing species occurrences. For each species, shaded cells indicate which factors were found to influence species occurrences in both permutations tests and BRT models (Fig. S1). Light grey shading indicates negative correlation between species occurrences and factor; dark grey shading indicates positive correlation between species occurrences and factor. Blank cells indicate factors identified by none or only one of the two analysis methods. "*" indicates main interactions between $\mathrm{CE} 1$ and the factor (two "** indicate medium importance interaction, four "*” main importance interaction (Fig. 3))

\begin{tabular}{|l|c|c|c|c|c|c|c|}
\hline Factor & las_ali & las_ema & las_neg & las_nig & las_par & tet_spe & tet_spu \\
\hline $\begin{array}{l}\text { LC1 } \\
\text { LC2 }\end{array}$ & & & & & $* *$ & & $* * *$ \\
\hline ST & & & & $* * *$ & & \\
\hline deltaLC & & & & & & & \\
\hline OHFrag & & & & & $* * * *$ & & \\
\hline $\begin{array}{l}\text { DBanks } \\
\text { DMainRoad } \\
\text { RoadsDensity }\end{array}$ & & & $* * * *$ & & & & \\
\hline CE1 & & & & & & \\
\hline
\end{tabular}

cryptic complex distributed all over Europe (Schlick-Steiner et al. 2006). T. sp.E is also known to be invasive in NorthAmerica since the early nineteenth century, and has been described as an urban specialist in its invasive range (King and Green 1995) but ecological preferences data in its native European range are scarce. Here, we showed that $T$. sp.E was indeed associated with urban environments, especially where open-vegetation patches were highly fragmented (Fig. 2, Table 6). OMI analysis also showed that $T$. sp.E had the largest niche breadth of all species (Table 4), which indicated its ability to tolerate a broad variety of environmental conditions. Globally, T. sp.E appeared the most urban exploiter species (Fig. 2, Fig. 4a), which raises questions about its status in Europe. Indeed, as pointed out by Valery et al. (2009), "invasive species can also be native" since species can, in response to environmental changes in their native range, show the same patterns of populations growth and spread than in their invasive ranges.

On the opposite, $T$. sp.U2 favored the less fragmented areas and showed the typical distribution pattern of an urban avoider (Fig. 2, Fig. 4a). However, we cannot exclude the possibility that the absence of $T$. sp.U2 in urban environments is the result of exclusive competition with $T$. sp.E. $T$. sp.U2 distribution was also affected by the interaction between surface temperature and climate, suggesting that, although this species was generally absent from urban environments in our study area, it might be favored by urban heat islands at higher latitudes or altitudes.

As expected, Lasius niger was the most generalist species, occupying almost $75 \%$ of all sampling locations and showing the lowest marginality. This species appeared to be significantly tied to newly vegetated areas (deltaLC), which was
Fig. 4 Spatial distribution of (a) the two cryptic Tetramorium species and (b) Lasius neglectus
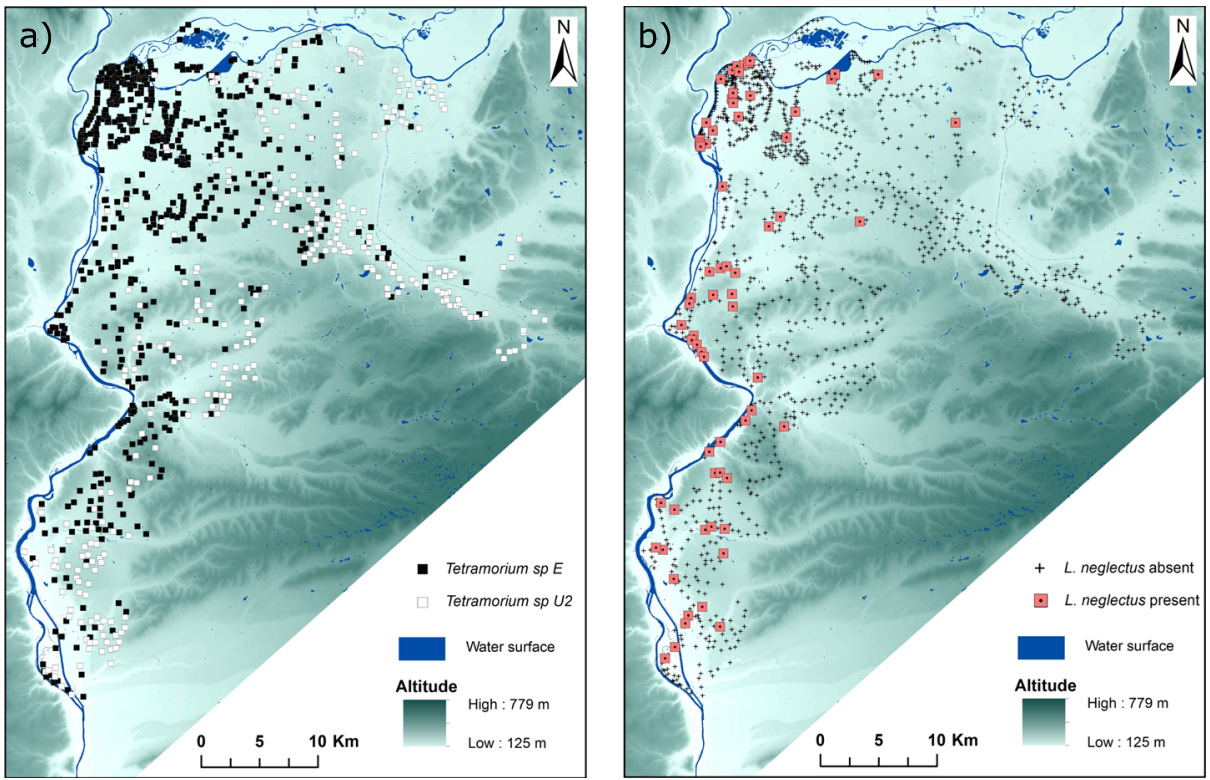
not surprising as most land cover changes from urban to vegetation occurred in dense urban areas: as a pioneering species inhabiting urban areas (Czechowski et al. 2013; Seifert 1991), L. niger is therefore likely to quickly recolonize these new environments. However, sites with $L$. niger tended to be more distant from embankments than expected by chance. This finding could reflect a competitive exclusion of $L$. niger by L. neglectus (the latter being on the contrary significantly tied to embankments) and highlights the possible negative impact of invasive species on biodiversity, Lasius neglectus having already been pointed out as a threat for native arthropods species, including other ants (Nagy et al. 2009).

The distributions of other native Lasius species (L. alienus, $L$. emarginatus and $L$. paralienus) were affected by very different sets of factors. Interestingly, all these species were absent from urban cores although they did not share any common explanative factor affecting their distribution, which illustrates the complexity of urbanization impacts on biodiversity. Additionally, Lasius paralienus appeared favored in cold climate agricultural landscapes (interaction between CE1 and LC2). As climate can influence agricultural practices and cultivated species phenology (Craufurd and Wheeler 2009), this relationship raises questions about ant responses to agricultural practices and crop species composition in agricultural landscapes (Peck et al. 1998).

As expected, L. neglectus distribution was driven by human activities factors. This is, to our knowledge, the first study indicating the importance of a factor such as the distance to embankments in explaining the spatial distribution of an invasive species. The invasive ant $L$. neglectus is characterized, like many other tramp ant species (e.g., Linepithema humile), by a high level of polygyny (several queens in one nest), supercolonial organization and very low self-dispersal abilities (Ugelvig et al. 2008). Unlike most ant species (including all the other species studied here), L. neglectus is incapable of dispersal by nuptial flight: supercolonies expand by budding, which consists in the increase of the area occupied by the supercolony over the years (Espadaler et al. 2007). This mechanism has been described as a short distance process (few meters to $89 \mathrm{~m}$ a year) and is thus very unlikely to explain the invasion pattern of $L$. neglectus throughout the landscape, as the median distance between the 69 invaded locations was $17.7 \mathrm{~km}$. The spatial distribution pattern of this species appears to be mostly due to human-mediated dispersal at reduced limited spatial scale (as 69 independent long distance introduction events are unlikely). Construction of embankments involves soil rearrangement and movement: ground dwelling arthropods, and particularly highly polygynous tramp ants are therefore likely to be displaced with queens, thus enabling colony survival and rapid growth in newly created embankments (King et al. 2009).

An alternative, although non-exclusive, mechanism could be responsible for the relationship between $L$. neglectus and embankments: as suggested by DeMers (1993), anthropogenic microhabitat structures, such as roads ditches or embankments, could act as corridors for range expansion of species experiencing climatic limitation as they reach their northern range limits. Embankments could make highly suitable environmental conditions because their structure is likely to modify abiotic conditions such as solar exposure (and therefore local temperature) or soil compaction and draining, as well as biotic factors such as plant community composition (Vasconcelos et al. 2014). Moreover, a recent study (Schaffers et al. 2012) showed that roadside verges, rather than acting as biodiversity sinks, appeared to be highly suitable reproduction and overwintering habitats for a wide range of arthropod taxa. L. neglectus showed higher probability of occurrence embankments located in hot/dry sites, than in cold/wet sites (interaction between Dbanks and CE, Fig. 3a). This observation strengthens the hypothesis that embankments act as human-mediated dispersal endpoints, rather than as warm shelters in a cold and rainy environment.

Because of the spatial scale of our study area, we did not expect strong and general effect of climate on ant species distributions. Remarkably, climatic effects (CE1) influenced the spatial distribution of 5 out of 7 species, highlighting that, even at reduced spatial scales, coarse environmental features can affect biodiversity patterns and consequently have to be taken into account. Furthermore, climatic effects often acted in interaction with factors associated with urbanization (Fig. 3). This suggested that, for a given species, the explanative combination of factors may depend on climatic context, which is likely to affect species responses to urbanization along latitudinal and altitudinal gradients. For example, a species could be defined as an urban avoider at lower latitudes (hot and dry) and an urban exploiter at higher latitudes (cold and wet); because urban heat island effects would turn urban environments into a more favorable habitat in the second case. This example was illustrated in our results by the interaction between climatic effects (CE1) and surface temperature for Tetramorium sp.U2.

\section{Conclusion}

Shochat et al. (2006) discussed the necessity for urban ecology to balance between descriptive and experimental (mechanistic) ecology in order to develop a better understanding of ecological and evolutionary processes operating in urbanized landscapes and ecosystems. Precisely identifying species-environment relationships in urbanized contexts is therefore a necessary logical step that should offer pertinent directions for future experimental studies (Stewart et al. 2015). Furthermore, it clearly appears that future urban ecology studies will have to deal with complex interactions between global changes (Radinger et al. 2015). Consequently, further studies 
focusing on the effects of urbanization on biodiversity should aim to compare urban areas, using multiple gradient (e.g., climate, human social and economic activities) sampling designs in order to better disentangle the many intricate factors affecting species distributions.

Acknowledgments The study was funded by the Conseil Départemental de l'Isère. This work was supported by the LABEX IMU (ANR-10-LABX-0088) of Université de Lyon, within the program "Investissements d'Avenir" (ANR-11-IDEX-0007) operated by the French National Research Agency (ANR). The authors wish to thank the many students and interns who participated in the extensive sampling and identification of ants over the years. Additional thanks to Aurélie Granjon for the first molecular identifications, to Jérôme Prunier, David Eme and Julien Grangier for constructive criticism of the first manuscript drafts. Finally, the authors wish to thank Charles Nilson and an anonymous reviewer who provided useful advices for improving the manuscript.

\section{References}

Alpert P, Bone E, Holzapfel C (2000) Invasiveness, invasibility and the role of environmental stress in the spread of non-native plants. Perspect Plant Ecol Evol Syst 3:52-66

Angold PG, Sadler JP, Hill MO, Pullin A, Rushton S, Austin K, Small E, Wood B, Wadsworth R, Sanderson R, Thompson K (2006) Biodiversity in urban habitat patches. Sci Total Environ 360:196204

Bang C, Faeth SH (2011) Variation in arthropod communities in response to urbanization: seven years of arthropod monitoring in a desert city. Landsc Urban Plan 103:383-399

Blair RB (1996) Land use and avian species diversity along an urban gradient. Ecol Appl 6:506

Boulton AM, Davies KF, Ward PS (2005) Species richness, abundance, and composition of ground-dwelling ants in northern California grasslands: role of plants, soil, and grazing. Environ Entomol 34: 96-104

Brown LR, Gregory MB, May JT (2009) Relation of urbanization to stream fish assemblages and species traits in nine metropolitan areas of the United States. Urban Ecosyst 12:391-416

Buczkowski G, Bennett G (2008) Seasonal polydomy in a polygynous supercolony of the odorous house ant, Tapinoma sessile. Ecol Entomol 33:780-788

Carpintero S, Reyes-López J (2014) Effect of park age, size, shape and isolation on ant assemblages in two cities of southern Spain. Entomol Sci 17:41-51

Casquet J, Thebaud C, Gillepie RG (2012) Chelex without boiling, a rapid and easy technique to obtain stable amplifiable DNA from small amounts of ethanol-stored spiders. Mol Ecol Resour 12:136 141

Clarke KM, Fisher BL, LeBuhn G (2008) The influence of urban park characteristics on ant (hymenoptera, Formicidae) communities. Urban Ecosyst 11:317-334

Cohen J (1960) A coefficient of agreement for nominal scales. Educ Psychol Meas 20:37-46

Conole LE (2014) Degree of adaptive response in urban tolerant birds shows influence of habitat-of-origin. PeerJ 2:e306

Core Team R (2014) A language and environment for statistical computing. R Foundation for Statistical Computing, Vienna

Craufurd PQ, Wheeler TR (2009) Climate change and the flowering time of annual crops. J Exp Bot 60:2529-2539
Croci S, Butet A, Georges A, Aguejdad R, Clergeau P (2008) Small urban woodlands as biodiversity conservation hot-spot: a multi-taxon approach. Landsc Ecol 23:1171-1186

Czechowski W, Vepsäläinen K, Radchenko A (2013) Ants on skerries: Lasius assemblages along primary succession. Insect Soc 60:147153

DeMers MN (1993) Roadside ditches as corridors for range expansion of the western harvester ant (Pogonomyrmex occidentalis Cresson). Landsc Ecol 8:93-102

Diallo-Dudek J, Lacaze B, Comby J (2015) Conference: 2015 joint urban remote sensing event (JURSE 2015). Institute of electrical and electronics engineers (IEEE):375p

Doledec S, Chessel D, Gimaret-Carpentier C (2000) Niche separation in community analysis: a new method. Ecology 81:2914-2927

Dousset B, Gourmelon F, Laaidi K, Zeghnoun A, Giraudet E, Bretin P, Mauri E, Vandentorren S (2011) Satellite monitoring of summer heat waves in the Paris metropolitan area. Int J Climatol 31:313-323

Dray S, Dufour A (2007) The ade 4 package: implementing the duality diagram for ecologists. J Stat Softw 22:1-20

Eeva T, Sorvari J, Koivunen V (2004) Effects of heavy metal pollution on red wood ant (Formica s. str.) populations. Environ Pollut 132:533539

Elith J, Graham CH, Anderson RP, et al. (2006) Novel methods improve prediction of species' distributions from occurrence data. Ecography 29:129-151

Elith J, Leathwick JR, Hastie T (2008) A working guide to boosted regression trees. J Anim Ecol 77:802-813

Espadaler X, Bernal V (2015) Lasius neglectus, a polygynous, sometimes invasive ant. http://www.creaf.uab.es/xeg/lasius/Ingles/distribution. htm. Last access: January 25, 2016.

Espadaler X, Tartally A, Schultz R, et al. (2007) Regional trends and preliminary results on the local expansion rate in the invasive garden ant, Lasius neglectus (Hymenoptera, Formicidae). Insect Soc 54: 293-301

Flinn KM, Vellend M (2005) Recovery of forest plant communities in post agricultural landscapes. Front Ecol Environ 3:243-250

Gaston KJ (2010) Urban ecology. In: Gaston KJ (ed) Urban ecology. Cambridge University Press, Cambridge, pp. 1-9

Grimm NB, Faeth SH, Golubiewski NE, Redman CL, Wu J, Bai X, Briggs JM (2008a) Global change and the ecology of cities. Science 319:756-760

Grimm NB, Foster D, Groffman P, Grove JM, Hopkinson CS, Nadelhoffer KJ, Pataki DE, Peters DPC (2008b) The changing landscape: ecosystem responses to urbanization and pollution across climatic and societal gradients. Front Ecol Environ 6:264-272

Guénard B, Cardinal-De Casas A, Dunn RR (2015) High diversity in an urban habitat: are some animal assemblages resilient to long-term anthropogenic change? Urban Ecosyst 18:449-463

Hansen AJ, Knight RL, Marzluff JM, Powell S, Brown K, Gude PH, Jones K (2005) Effects of exurban development on biodiversity: patterns, mechanisms, and research needs. Ecol Appl 15:1893-1905

Heterick BE, Lythe M, Smithyman C (2013) Urbanisation factors impacting on ant (Hymenoptera: Formicidae) biodiversity in the Perth metropolitan area, Western Australia: two case studies. Urban Ecosyst 16:145-173

Hijmans RJ, Cameron SE, Parra JL, Jones PG, Jarvis A (2005) Very high resolution interpolated climate surfaces for global land areas. Int $\mathrm{J}$ Climatol 25:1965-1978

Hijmans RJ, Phillips S, Leathwick J, Elith J (2011) Package 'dismo'. Available online at: http://cran.r-project. org/web/packages/dismo/index.html.

Hodkinson DJ, Thompson K (1997) Plant dispersal: the role of man. J Appl Ecol 34:1484-1496

Infoclimat.fr (2011) http://www.infoclimat.fr/stations-meteo/climatomoyennes-records.php?staid $=07480 \&$ from $=1981 \&$ to $=2010$ \&redirect=1. Last access: January 25, 2016. 
James P, Bound D (2009) Urban morphology types and open space distribution in urban core areas. Urban Ecosyst 12:417-424

Jenerette GD, Potere D (2010) Global analysis and simulation of land-use change associated with urbanization. Landsc Ecol 25:657-670

Joseph LN, Field SA, Wilcox C, Possingham HP (2006) Presenceabsence versus abundance data for monitoring threatened species. Conserv Biol 20:1679-1687

Kark S, Iwaniuk A, Schalimtzek A, Banker E (2007) Living in the city: can anyone become an urban exploiter'? J Biogeogr 34:638-651

King TG, Green SC (1995) Factors affecting the distribution of pavement ants (Hymenoptera: Formicidae) in Atlantic coast. Entomol News 106:224-228

King JR, Tschinkel WR, Ross KG (2009) A case study of human exacerbation of the invasive species problem: transport and establishment of polygyne fire ants in Tallahassee, Florida, USA. Biol Invasions 11:373-377

Leathwick JR, Elith J, Chadderton WL, Rowe D, Hastie T (2008) Dispersal, disturbance and the contrasting biogeographies of New Zealand's diadromous and non-diadromous fish species. J Biogeogr 35:1481-1497

McDonnell MJ, Hahs AK (2008) The use of gradient analysis studies in advancing our understanding of the ecology of urbanizing landscapes: current status and future directions. Landsc Ecol 23:11431155

McIntyre NE (2000) Ecology of urban arthropods: a review and a call to action. Ann Entomol Soc Am 93:825-835

McKinney ML (2008) Effects of urbanization on species richness: a review of plants and animals. Urban Ecosyst 11:161-176

Menke SB, Guénard B, Sexton JO, Weiser MD, Dunn RR, Silverman J (2011) Urban areas may serve as habitat and corridors for dryadapted, heat tolerant species; an example from ants. Urban Ecosyst 14:135-163

Nagy C, Tartally A, Vilisics F, et al. (2009) Effects of the invasive garden ant, Lasius neglectus VAN LOON, BOOSMA \& ANDRÁSFALVY, 1990 (Hymenoptera: Formicidae), on arthropod assemblages: pattern analyses in the type supercolony. Myrmecological News 12:171-181

Niemelä J, Kotze DJ (2009) Carabid beetle assemblages along urban to rural gradients: a review. Landsc Urban Plan 92:65-71

Oleson KW, Monaghan A, Wilhelmi O, Barlage M, Brunsell N, Feddema J, Hu L, Steinhoff DF (2015) Interactions between urbanization, heat stress, and climate change. Clim Chang 129:525-541

Pećarević M, Danoff-Burg J, Dunn RR (2010) Biodiversity on Broadway - enigmatic diversity of the societies of ants (Formicidae) on the streets of New York City. PLoS One 5:1-8

Peck SL, McQuaid B, Campbell CL (1998) Using ant species (Hymenoptera: Formicidae) as a biological indicator of agroecosystem condition. Environ Entomol 27:1102-1110

Philpott SM, Cotton J, Bichier P, Friedrich RL, Moorhead LC, Uno S, Valdez M (2014) Local and landscape drivers of arthropod abundance, richness, and trophic composition in urban habitats. Urban Ecosyst 17:513-532

Poff NL (1997) Landscape filters and species traits: towards mechanistic understanding and prediction in stream ecology. J North Am Benthol Soc 16:391

Prasad AM, Iverson LR, Peters MP, Bossenbroek JM, Matthews SN, Sydnor TD, Schwartz MW (2010) Modeling the invasive emerald ash borer risk of spread using a spatially explicit cellular model. Landsc Ecol 25:353-369

Radinger J, Hölker F, Horký P, Slavik OJ, Dendoncker N, Wolter C (2015) Synergistic and antagonistic interactions of future land use and climate change on river fish assemblages. Glob Chang Biol 22: $1505-1522$

Rouifed S, Piola F, Spiegelberger T (2014) Invasion by Fallopia spp. in a French upland region is related to anthropogenic disturbances. Basic Appl Ecol 15:435-443
Roura-Pascual N, Brotons L, Peterson AT, Thuiller W (2009) Consensual predictions of potential distributional areas for invasive species: a case study of argentine ants in the Iberian peninsula. Biol Invasions 11:1017-1031

Savage AM, Hackett B, Guénard B, Youngsteadt EK, Dunn RR (2015) Fine-scale heterogeneity across Manhattan's urban habitat mosaic is associated with variation in ant composition and richness. Insect Conserv Divers 8:216-228

Schaffers AP, Raemakers IP, Sýkora KV (2012) Successful overwintering of arthropods in roadside verges. J Insect Conserv 16:511-522

Schlick-Steiner BC, Steiner FM, Moder K, et al. (2006) A multidisciplinary approach reveals cryptic diversity in western Palearctic Tetramorium ants (Hymenoptera: Formicidae). Mol Phylogenet Evol 40:259-273

Seifert B (1991) Lasius platythorax N. Sp. a widespread sibling species of Lasius niger (Hymenoptera: Formicidae). Entomol Gener 16:69-81

Seifert B (2007) Die Ameisen Mittel- und Nordeuropas. Lutra Verlagsund Vertriebsgesellschaft, Tauer 368p

Shochat E, Warren P, Faeth S, McIntyre NE, Hope D (2006) From patterns to emerging processes in mechanistic urban ecology. Trends Ecol Evol 21:186-191

Simon C, Frati F, Beckenbach A, Crespi B, Liu H, Flook P (1994) Evolution, weighting, and phylogenetic utility of mitochondrial gene-sequences and a compilation of conserved polymerase chain reaction primers. Ann Entomol Soc America 87:651-701

Ślipiński P, ZMihorski M, Czechowski W (2012) Species diversity and nestedness of ant assemblages in an urban environment. Eur J Entomol 109:197-206

Smith LS, Broyles MEJ, Larzleer HK, Fellowes MDE (2015) Adding ecological value to the urban lawnscape. Insect abundance and diversity in grass-free lawns. Biodivers Conserv 24:47-62

Steiner FM, Schlick-Steiner BC, VanDerWal J, et al. (2008) Combined modelling of distribution and niche in invasion biology: a case study of two invasive Tetramorium ant species. Divers Distrib 14:538-545

Stewart DR, Walters AW, Rahel FJ (2015) Landscape-scale determinants of native and non-native Great Plains fish distributions. Divers Distrib 22:225-238

Stringer LD, Stephens AEA, Suckling DM, Charles JG (2009) Ant dominance in urban areas. Urban Ecosyst 12:503-514

Suarez AV, Bolger DT, Case TJ (1998) Effects of fragmentation and invasion on native ant communities in coastal Southern California. Ecology 79:2041-2056

Turrini T, Knop E (2015) A landscape ecology approach identifies important drivers of urban biodiversity. Glob Chang Biol 21:16521667

Ugelvig LV, Drijfhout FP, Kronauer DJ, et al. (2008) The introduction history of invasive garden ants in Europe: integrating genetic, chemical and behavioural approaches. BMC Biol 6:11

Uno S, Cotton J, Philpott SM (2010) Diversity, abundance, and species composition of ants in urban green spaces. Urban Ecosyst 13:425441

Valery L, Fritz H, Lefeuvre J-C, Simberloff D (2009) Invasive species can also be native... Trends Ecol Evol 24:585-586

Van Nuland ME, Whitlow WL (2014) Temporal effects on biodiversity and composition of arthropod communities along an urban-rural gradient. Urban Ecosyst 17:1047-1060

Vasconcelos PB, Araújo GM, Bruna EM (2014) The role of roadsides in conserving Cerrado plant diversity. Biodivers Conserv 23:30353050

Vepsäläinen K, Ikonen H, Koivula MJ (2008) The structure of ant assemblages in an urban area of Helsinki, southern Finland. Ann Zool Fennici 45:109-127 
Verberk WCEP, van Noordwijk CGE, Hildrew AG (2013) Delivering on a promise: integrating species traits to transform descriptive community ecology into a predictive science. Freshw Sci 32:531-547

Vergnes A, Le Viol I, Clergeau P (2012) Green corridors in urban landscapes affect the arthropod communities of domestic gardens. Biol Conserv 145:171-178

Vonshak M, Gordon DM (2015) Intermediate disturbance promotes invasive ant abundance. Biol Conserv 186:359-367

Ward PS (1987) Distribution of the introduced argentine ant (Iridomyrmex humilis) in natural habitats of the lower
Sacramento Valley and its effects on the indigenous ant fauna. Hilgardia 55(2):1-16

With KA (2002) The landscape ecology of invasive spread. Conserv Biol 16:1192-1203

Yamaguchi T (2005) Influence of urbanization on ant distribution in parks of Tokyo and Chiba City, Japan II. Analysis of species. Entomol Sci $8: 17-25$

Youngsteadt E, Henderson RC, Savage AM, Ernst AF, Dunn RR, Frank SD (2014) Habitat and species identity, not diversity, predict the extent of refuse consumption by urban arthropods. Glob Chang Biol 21:1103-1115 